\title{
MiR-142-3p Functions as a Potential Tumor Suppressor in Human Osteosarcoma by Targeting HMGA1
}

\author{
Guoxing $\mathrm{Xu}^{\mathrm{a}, \mathrm{c}}$ Jin Wang ${ }^{\mathrm{a}, \mathrm{c}}$ Yixin Jia ${ }^{\mathrm{a}, \mathrm{c}}$ Feng Shen ${ }^{\mathrm{a}}$ Wensheng Han ${ }^{\mathrm{b}}$ \\ Yifan Kang ${ }^{a}$
}

aDepartment of Orthopedics, Changhai Hospital, Second Military Medical University, Shanghai, bDepartment of Orthopedics, Yantai Affiliated Hospital of Binzhou Medial University, Yantai, China; These authors contribute equally to this work

\section{Key Words}

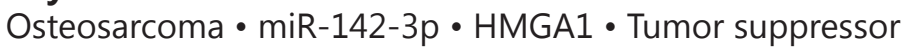

\begin{abstract}
Background/Aims: Mounting evidence has shown that aberrant expression of miRNAs correlates with human cancers, and that miRNAs can function as tumor suppressors or oncogenes. Here, we investigated the role and mechanism of miR-142-3p in human osteosarcoma. Methods: We used quantitative real-time RT-PCR to measure the expression of miR-142-3p in human osteosarcoma cell lines and tissues. The roles of miR-142-3p in osteosarcoma development were studied using cultured HOS, MG63 and Saos-2 cells and tumor xenograft analyses in nude mice; their target genes were also investigated. Results: We found that miR-142-3p was significantly downregulated in osteosarcoma cell lines and clinical specimens. Overexpression of miR-142-3p suppressed osteosarcoma cell proliferation, migration and invasion, whereas miR-142-3p knockdown increased these parameters. The xenograft mouse model also revealed the suppressive effect of miR-142-3p on tumor growth. High mobility group AT-hook 1 (HMGA1) was identified as a target of miR-142-3p. Downregulation of HMGA1 induced effects on osteosarcoma cell lines similar to those induced by miR-142-3p. In contrast, restoration of HMGA1 abrogated the effects induced by miR-142$3 p$ up-regulation. Conclusion: These results indicated that miR-142-3p may function as a tumor suppressor by targeting HMGA1 in osteosarcoma.
\end{abstract}




\section{Introduction}

Osteosarcoma is the most common form of primary bone cancer and usually develops in growing bones, which constitutes the main cause of cancer death in adolescents [1]. Phenotypically, osteosarcoma is relatively homogeneous, but multiple genetic and environmental factors contribute to its development [2,3]. It commonly occurs in the long bones near the metaphyseal growth plates and tumor initiation is thought to be connected to bone growth. High grade tumors are highly metastatic, particularly to the lungs, with many cases of recurrence or relapse. Osteosarcoma is also notorious for chemoresistance. Consequently the survival rate has not improved since 1990, remaining at $60-70 \%$ at 5 years for patients with no metastatic disease, and being significantly worse for those with metastasis [4]. Therefore, there is a critical need for new molecular targets and approaches to treat this disease.

MicroRNAs (miRNAs) are short, non-coding RNA sequences 19 to 25 nucleotides long, which bind to complementary sequences generally located within the 3' untranslated region (UTR) of target transcript RNAs to act as critical post-transcriptional regulators of gene expression, inhibiting translation or reducing stability and inducing degradation [5]. There is accumulating evidence that miRNAs are involved in tumor pathogenesis, with approximately half of all miRNAs known to date being located within fragile sites and genomic regions associated with cancer [6,7]. Deregulation of miRNA expression has been associated with carcinogenesis $[7,8]$ and abnormal expression of miRNAs has been demonstrated in most tumor types $[6,9]$. In osteosarcoma, specific miRNA expression has been analyzed in tumor cell lines as well as in primary human samples and fixed specimens [10-12]. Multiple miRNAs including miR-199a-3p, miR-221, miR-34c and miR-16 have been implicated in the development of osteosarcoma, which function as tumor suppressors or oncogenes [13-16].

miR-142-3p has been reported to be down-regulated and serve as a potential tumor suppressor in several distinct cancer types including hepatocellular carcinoma (HCC), acute myeloid leukemia (AML), colon cancer and pancreatic ductal adenocarcinoma (PDAC) [1720]. Furthermore, Namløs et al. found that miR-142-3p was significantly downregulated in osteosarcoma cell lines compared to normal bone tissues by miRNA microarray analysis [21]. However, the role and molecular mechanism of miR-142-3p in osteosarcoma remain largely unknown.

In this study, we investigated miR-142-3p expression in osteosarcoma, and then analyzed the effect of miR-142-3p overexpression or knockdown on cell proliferation, migration and invasion. Furthermore, we identified the downstream target of miR-142-3p and investigated its role in regulating proliferation and invasion.

\section{Materials and Methods}

\section{Cell lines and human tissues}

The osteosarcoma cell lines HOS, MG63, U-20S, Saos-2 and 143B were purchased from the American Type Culture Collection (ATCC). Human osteoblasts (HOB) were from PromoCell (Heidelberg, Germany). Osteosarcoma cell lines were cultured in RPMI 1640 medium supplemented with $10 \%$ fetal bovine serum and 100 units $/ \mathrm{ml}$ of penicillin/streptomycin (Invitrogen, Carlsbad, CA, USA). HOB cells were cultured in Osteoblast Growth Medium (Promocell). All cells were cultured at $37^{\circ} \mathrm{C}$ in a humidified incubator containing $5 \% \mathrm{CO}_{2}$. Human primary osteosarcoma and matched adjacent normal tissues were collected from Changhai Hospital (Shanghai, China). Informed consent was obtained from each patient, and the experiments were approved by the ethics committee of Second Military Medical University, Shanghai, China.

\section{Quantitative real-time RT-PCR ( $q R T-P C R$ )}

qRT-PCR assay was performed as previously described [13]. For mature miR-142-3p detection, cDNA reverse transcription was carried out from total RNAs using specific miRNA primers and reagents from the TaqMan MicroRNA Reverse Transcription Kit (Applied Biosystems, Foster City, CA, USA). The resulting 


\begin{tabular}{|c|c|c|}
\hline Cellular Physiology & Cell Physiol Biochem 2014;33:1329-1339 & \\
\hline and Biochemistry & $\begin{array}{l}\text { DoI: 10.1159/000358700 } \\
\text { Published onine: April Z8, } 2014\end{array}$ & $\begin{array}{l}\text { O } 2014 \text { S. Karger AG, Basel } \\
\text { www.karger.com/cpb }\end{array}$ \\
\hline
\end{tabular}

cDNA was amplified by PCR using TaqMan miR-142a-3p MicroRNA Assay primers and measured in the PRISM 7900HT system (Applied Biosystems). U6 was used as the internal control. For HMGA1 mRNA quantification, qRT-PCR was performed using the QuantiFast SYBR Green RT-PCR kits (QIAGEN, Germany). $\beta$-actin was used as an internal control. All reactions were carried out in triplicate.

\section{Plasmids and transfection}

The HMGA1 3'-UTR from 42 to 554 bp was generated by PCR amplification and subcloned into the pGL3-control luciferase reporter plasmid (Promega, Madison, WI, USA). The corresponding mutant constructs were created by mutating the seed regions of the miR-142-3p-binding sites. The plasmid pcDNA3.1(+)-HMGA1 was constructed by inserting the HMGA1 cDNA without $3^{\prime}$-UTR into the pcDNA3.1(+) vector (Invitrogen). The miR-142-3p mimics, anti-miR-142-3p and the corresponding negative control were synthesised by Genepharma (Shanghai, China). HMGA1 siRNAs were purchased from Ribobo (Guangzhou, China). Transfection of plasmids or oligonucleotides was performed using the Lipofectamine 2000 reagent (Invitrogen) according to the manufacturer's instruction. The cells were harvested for assays $48 \mathrm{~h}$ after transfection.

\section{Cell proliferation and colony formation assays}

Cell proliferation was assessed using the Cell Counting Kit-8 (CCK-8) assay. Harvested cells were plated in 96-well plates $\left(2 \times 10^{3}\right.$ cells/well) and incubated for $24,48,72$ and $96 \mathrm{~h}$ after transfection. CCK8 solution $(10 \mu \mathrm{L})$ was then added to each well, and cells were incubated for another $4 \mathrm{~h}$ at $37^{\circ} \mathrm{C}$. Then absorbance at $450 \mathrm{~nm}$ was measured to calculate the number of viable cells. For colony formation assay, cells were trypsinized and seeded on 6 -well plates (200 cells/well). After 2 weeks, the colonies were stained with $1 \%$ crystal violet for 30 s and the number of colonies was counted. The experiments were performed independently in triplicate.

\section{Cell migration and invasion assays}

Cell migration and invasion assays were performed as previously described using a 24-well transwell plate (8-mm pore size, Corning, New York, USA) [22]. For transwell migration assay, $2.5 \times 10^{4}$ cells were plated in the top chamber lined with a non-coated membrane. For invasion assay, chamber inserts were coated with $200 \mathrm{mg} / \mathrm{ml}$ of Matrigel, and then $5 \times 10^{4}$ cells were plated in the top chamber. After $24 \mathrm{~h}$ incubation, the cells that migrated or invaded through the membrane were fixed with methanol, stained with crystal violet, and counted under a microscope (Olympus Corp., Tokyo, Japan). The results were averaged among three independent experiments.

\section{Western blotting}

Cell-lysates were collected in RIPA lysis buffer. Per lane 30-60 $\mu \mathrm{g}$ of whole cell lysate was separated on $10 \%$ SDS-PAGE and transferred on PVDF membranes (Millipore, Danvers, MA, USA). Blots were blocked with $5 \%$ non-fat dried milk, and then incubated overnight at $4^{\circ} \mathrm{C}$ with primary antibodies against HMGA1 or $\beta$-actin (Abcam, Cambridge, MA, USA). Next day the membrane was incubated with a secondary antibody conjugated with horseradish peroxidase (Santa Cruz Biotechnology, Santa Cruz, CA, USA). The bands were visualized using an enhanced chemiluminescence (ECL) system (GE Healthcare, Little Chalfont, UK).

\section{Luciferase reporter assay}

Osteosarcoma cell lines HOB and MG63 were seeded in 24-well plates and then cotransfected with either miR-142-3p mimics or negative control, 50 ng of either pGL3-HMGA1-3'UTR-wt or pGL3-HMGA1$3^{\prime}$ UTR-mut and $10 \mathrm{ng}$ of pRL-TK (Promega). Luciferase and renilla signals were measured $48 \mathrm{~h}$ after transfection using the Dual Luciferase Reporter Assay Kit (Promega). All experiments were performed in triplicate.

Establishment of miR-142-3p-overexpression stable cells

Recombinant lentiviruses including miR-142-3p-lentivirus and the negative control pGC FU-GFP-LV were purchased from Shanghai GeneChem Company (Shanghai, China). They were used to infect HOS cells, and the stably transfected cells were selected using puromycin $(1.5 \mu \mathrm{g} / \mathrm{mL})$ and confirmed by qRT-PCR. 


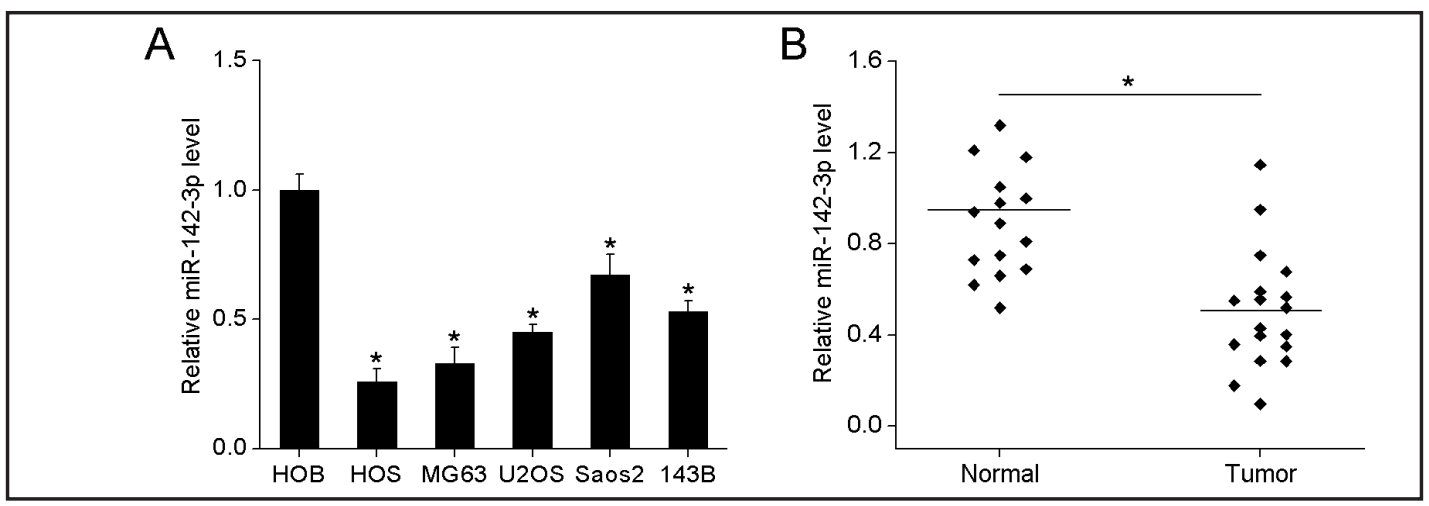

Fig. 1. The levels of mature miR-142-3p expression in osteosarcoma cell lines and tissues. (A) Expression levels of miR-142-3p were measured by qRT-PCR in osteoblasts and in five osteosarcoma cell lines. (B) Expression levels of miR-142-3p in 16 pairs of osteosarcoma and adjacent non-cancerous tissues. ${ }^{*} P<0.05$.

\section{In vivo models}

HOS cells stably overexpressing miR-142-3p or NC were harvested and resuspended in sterile phosphate buffered saline (PBS), then a suspension of $1 \times 10^{6}$ cells $(100 \mu \mathrm{L})$ was injected subcutaneously into the scapula of each mouse $(n=5)$. Tumor size was calculated every 5 days, and the volume was calculated using the formula $\mathrm{LW}^{2} / 2$ (where $\mathrm{L}$ and $\mathrm{W}$ represent the length and width of the tumor). All mice were sacrificed 25 days later, and the tumors were extracted to determine tumor weight. The experiments were undertaken in accordance with the National Institute of Health Guide for the Care and Use of Laboratory Animals, with the approval of the Scientific Investigation Board of Second Military Medical University, Shanghai, China.

\section{Statistical analysis}

All data are presented as the mean \pm SD. Differences between groups was analyzed by Student's $t$-test when comparing only two groups or one-way analysis of variance (ANOVA) when comparing more than two groups. Spearman's correlation analyses were used to analyze the relationship between miR-142-3p expression and HMGA1 expression. $P$ values $<0.05$ were considered to be significant.

\section{Results}

miR-142-3p is downregulated in osteosarcoma cell lines and clinical specimens

Expression levels of miR-142-3p in the osteosarcoma cell lines HOS, MG63, U-20S, Saos-2 and 143B were analyzed by qRT-PCR and compared to expression in normal human osteoblasts (HOB). Using the same technique, miR-142-3p expression was compared between primary osteosarcoma samples and paired adjacent normal tissues. As shown in Fig. 1A, the expression of miR-142-3p in the osteosarcoma cell lines was lower than in normal osteoblasts. Similarly, the overall average expression levels of miR-142-3p were lower in primary samples compared to normal tissues (Fig. 1B). Collectively, these results suggest that miR-142-3p is downregulated in osteosarcoma.

\section{miR-142-3p suppresses osteosarcoma cell proliferation in vitro}

To investigate the role of miR-142-3p in growth of osteosarcoma, HOS and MG63 cell lines were transiently transfected with miR-142-3p mimics or negative control (NC), then analyzed by qRT-PCR to confirm increases in expression (Fig. 2A). Both CCK-8 assay and colony-formation assay demonstrated that overexpression of miR-142-3p significantly decreased the growth rate of HOS and MG63 cell lines (Fig. 2B-D). Confirmation of this effect was provided by the inverse experiment, in which Saos-2 cells were transfected with 


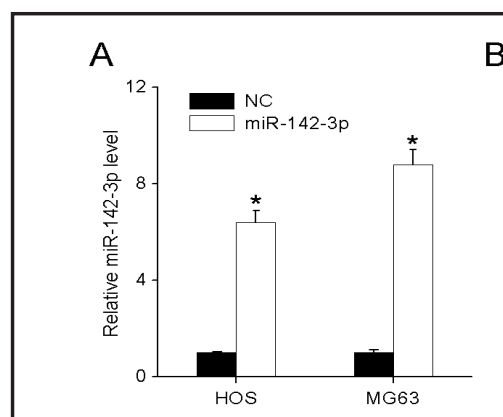

C
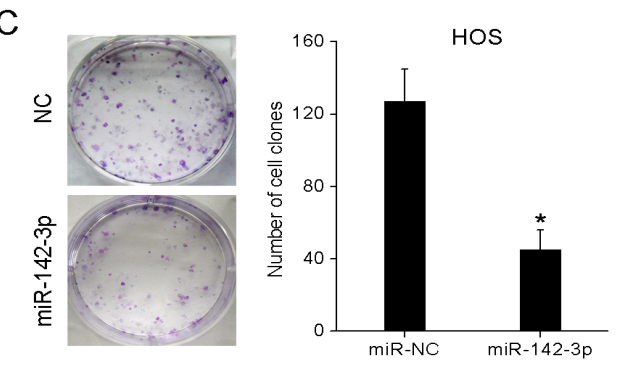

E

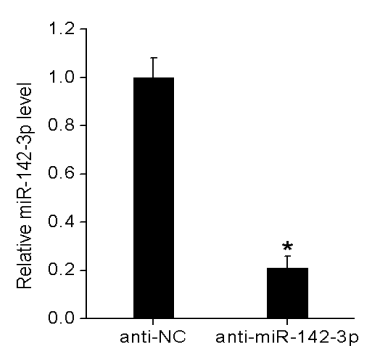

D
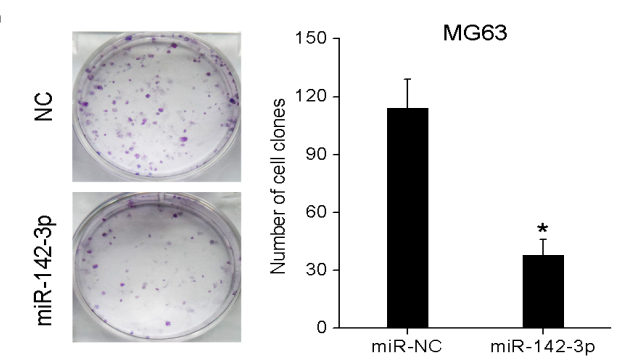

$\mathrm{B}$
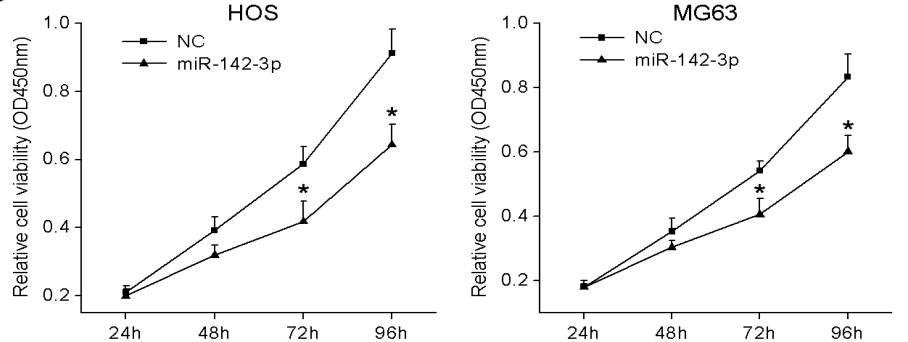

$\mathrm{F}$

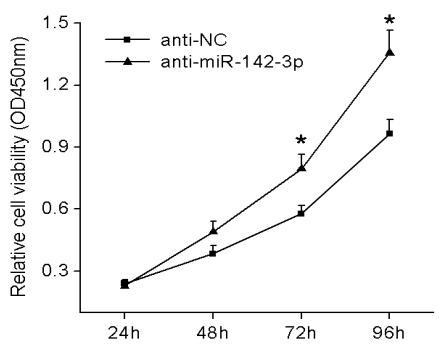

(c) 2014 S. Karger AG, Basel

www.karger.com/cpb

-

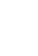



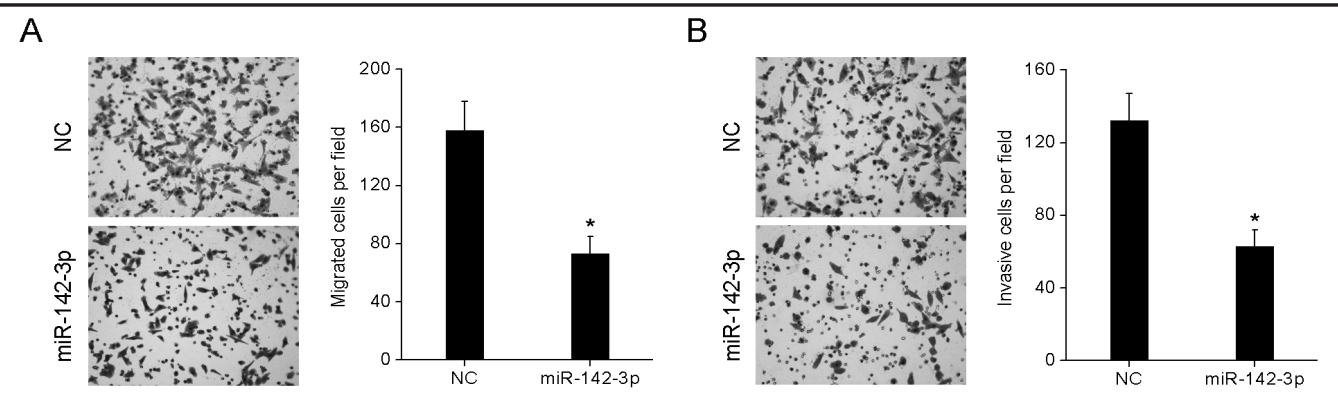

$\mathrm{C}$
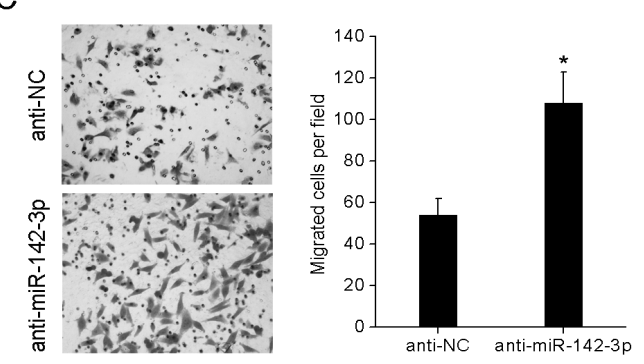

$\mathrm{D}$
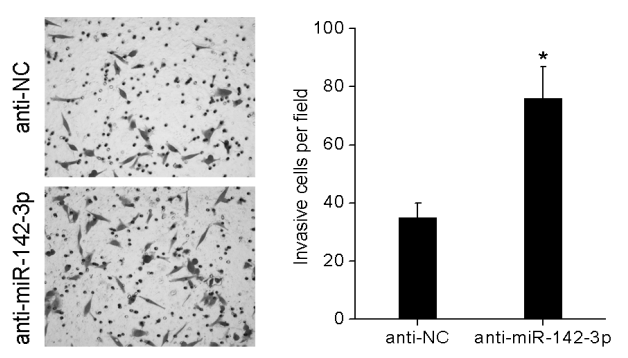

Fig. 3. The effects of miR-142-3p on in vitro migration and invasion of osteosarcoma cells. (A, B) Transwell migration and invasion assays of HOS cells transfected with miR-142-3p mimics or NC. Representative images are shown on the left, and the quantification of five randomly selected fields is shown on the right. (C, D) Transwell migration and invasion assays of Saos-2 cells transfected with anti-miR-142-3p or anti-NC. $* P<0.05$.

PicTar and miRanda. Among the genes identified, HMGA1 was of particular interest because of its positive roles in cancer cell proliferation and invasion [23]. miRNA alignment analysis revealed that the $3^{\prime}$-UTR of HMGA1 contains a putative binding site for miR-142-3p (Fig. 4A). Dual luciferase assays revealed that miR-142-3p overexpression induced a clear reduction of the HMGA1 3'-UTR luciferase reporter activity, whereas in the counterpart with the mutated site the luciferase activity was not significantly changed (Fig. 4B). Western blotting analyses confirmed down-regulation of HMGA1 expression in HOS and MG63 cell lines as a result of transfection with miR-142-3p minics. (Fig. 4C). These results suggested that miR-142$3 p$ could directly target HMGA1 in osteosarcoma cells through interaction with its 3 '-UTR. To further explore whether the findings above are supported by observations in human primary tumors, the correlation between miR-142-3p expression and HMGA1 expression was analyzed in 10 osteosarcoma tissues (Fig. 4D). Fig. 4E shows that miR-142-3p expression negatively correlated with the expression of HMGA1 $(r=-0.8868, P<0.001)$.

The antitumor effects of miR-142-3p are mediated through the repression of HMGA1

Based on the findings above, we hypothesized that miR-142-3p might inhibit osteosarcoma cell proliferation, migration and invasion by repressing HMGA1 expression. First we transiently transfected HMGA1 siRNA into HOS cells, and qRT-PCR and western blotting confirmed the downregulation of HMGA1 (Fig. 5A). As shown in Fig. 5B, HMGA1 silencing significantly suppressed cell proliferation, migration and invasion of HOS cells, which was similar to the phenotype induced by miR-142-3p. Subsequently, we performed gain-of-function experiments wherein HMGA1 was overexpressed using a cDNA lacking $3^{\prime}$ UTR (Fig. 5C). The result showed that HMGA1 overexpression could partially abrogate the antitumor effect of miR-142-3p in HOS cells (Fig. 5D). Taken together, these findings suggest that HMGA1 is a functional target for miR-142-3p in osteosarcoma cells. 


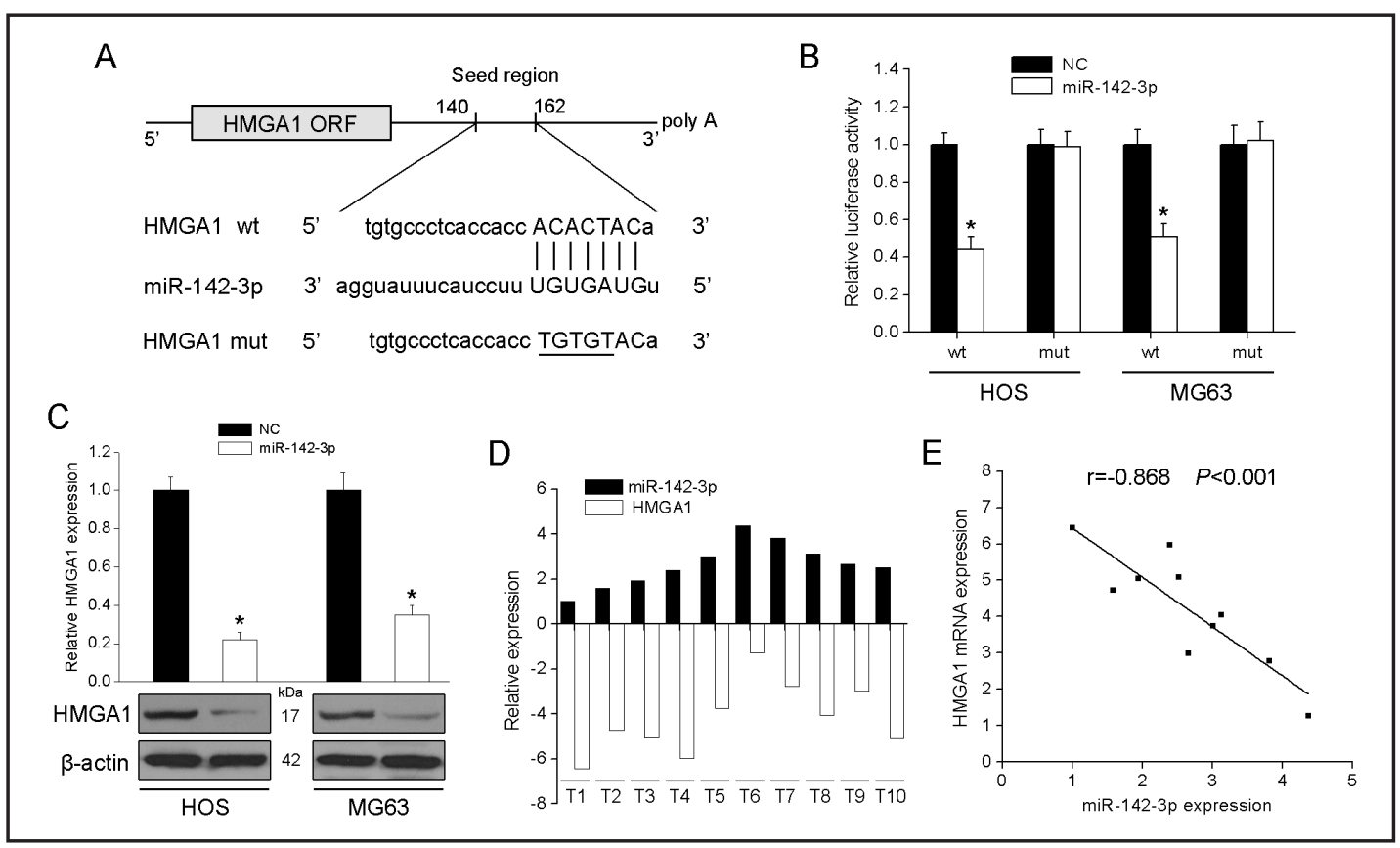

Fig. 4. HMGA1 is a direct target of miR-142-3p. (A) miR-142-3p and its putative binding sequences in the 3'-UTR of HMGA1. Mutations were generated in the complementary site that binds to the seed region of miR-142-3p. (B) Luciferase reporter assay in HOS and MG63 cells revealed that miR-142-3p overexpression suppressed the activity of firefly luciferase that carried the wild-type (wt) but not mutant (mut) 3'UTR of HMGA1. (C) Quantification of HMGA1 mRNA/protein expression in HOS and MG63 cells transfected with miR-142-3p mimics or NC by qRT-PCR and western blot. (D) qRT-PCR analysis of miR-142-3p and HMGA1 expression in the 10 human osteosarcoma tissues. (E) Spearman correlation analyses between relative miR142-3p expression and relative HMGA1 mRNA expression in 10 osteosarcoma tissues. $* P<0.05$.

miR-142-3p inhibits tumor growth in xenograft model of osteosarcoma

To further evaluate the effects of miR-142-3p on tumor growth in vivo, we engineered HOS cells to stably overexpress miR-142-3p by lentivirus infection. These cells and control cells were inoculated subcutaneously into the scapula of each mouse respectively $(n=5)$. As shown in Fig. 6A-C, the tumors formed by miR-142-3p-overexpressing HOS cells were smaller and had lower tumor weights than control tumors. qRT-PCR and western blotting analyses of the tumor tissues confirmed elevated miR-142-3p with reduced HMGA1 protein in miR-142-3p-overexpressing tumors (Fig. 6D,E). Furthermore, a similar inhibition in tumor growth was observed in the HMGA1 siRNA group but not in the control group (Fig. 7).

\section{Discussion}

Accumulating evidence has shown that miRNAs are involved in the development of human cancers. Functional studies have directly provided information on the potent pro- and anti-tumorigenic effects of specific miRNAs both in vitro and in vivo; therefore, miRNAs can function as tumor suppressors and oncogenes [7]. Recently, it was reported that miR-142$3 p$ is down-regulated in many human cancers [17-19]. Several studies have also evaluated the tumor-suppressive role of miR-142-3p $[17,19,20]$. For instance, Wu et al. reported that miR-142-3p suppresses the migration and invasion of hepatocellular carcinoma cells by regulating RAC1, a GTPase involved in cell growth, migration, and the activation of protein kinases [17]. Shen et al. showed that miR-142-3p inhibits the growth of colon cancer cells by targeting CD133, ABCG2, and Lgr5 [19]. MacKenzie et al. demonstrated that miR-142-3p 
A

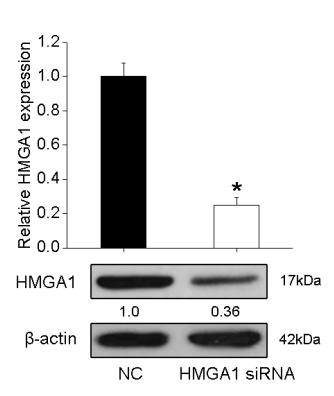

$\mathrm{C}$

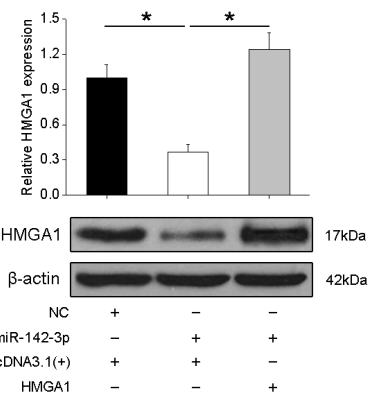

B

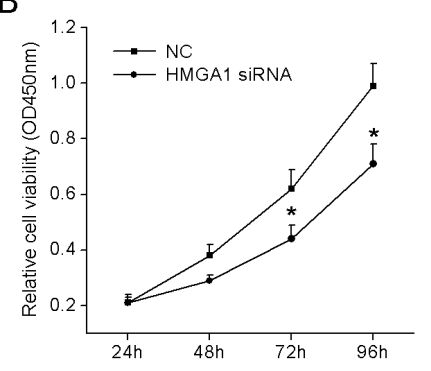

D

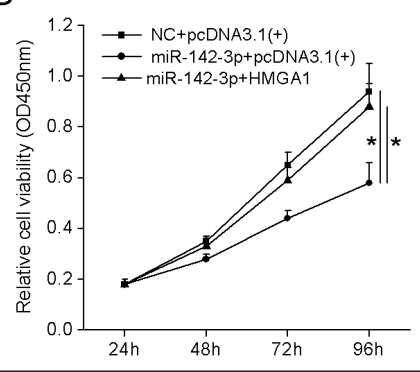

(C) 2014 S. Karger AG, Basel

www.karger.com/cpb
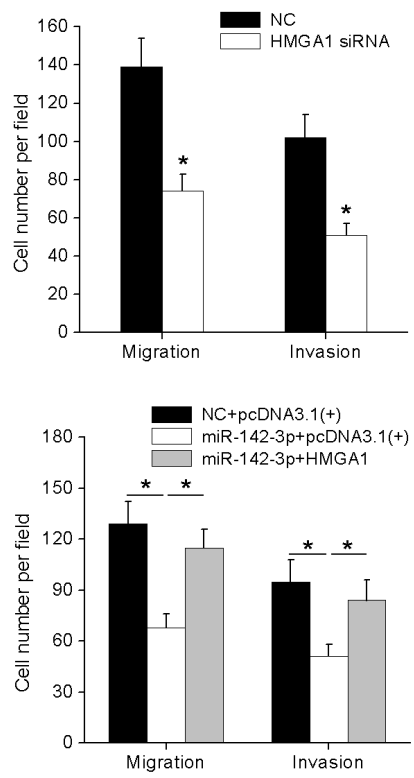

Fig. 5. HMGA1 is involved in miR-142-3p-inhibited growth, migration and invasion in HOS cells. (A) qRTPCR and western blotting analysis of HMGA1 expression in HOS cells transfected with HMGA1 siRNA or negative control (NC). (B) Downregulation of HMGA1 suppressed cell proliferation, migration and invasion of HOS cells. (C) HOS cells were transfected with miR-142-3p or NC along with HMGA1 plasmid (without $3^{\prime} \mathrm{UTR}$ ), and qRT-PCR and western blotting was performed $48 \mathrm{~h}$ after transfection. (D) Re-expression of HMGA1 rescued the suppressive effect of miR-142-3p on cell proliferation, migration and invasion of HOS cells. ${ }^{*} P<0.05$.

A

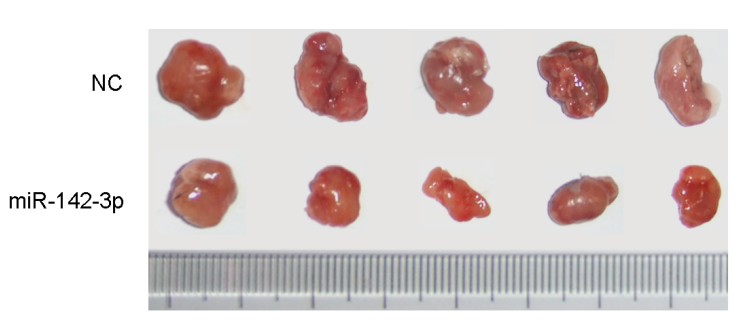

B

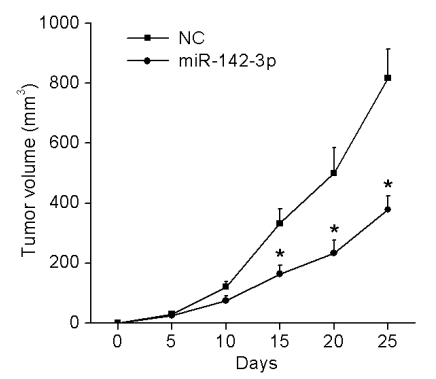

$\mathrm{E}$

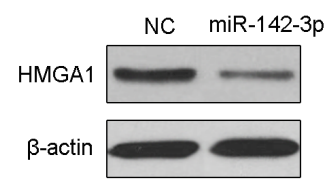

$\mathrm{D}$

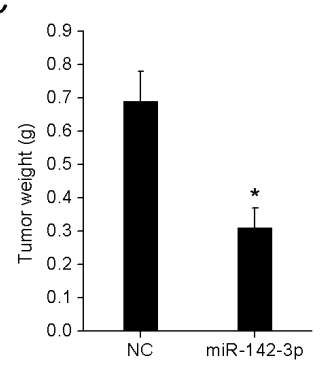

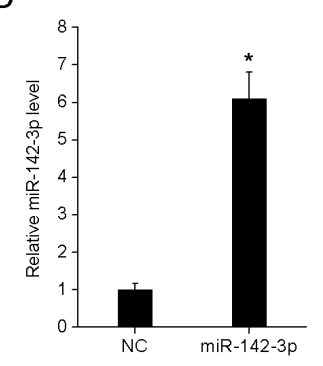

Fig. 6. miR-142-3p suppresses tumor growth in vivo. HOS cells $\left(2 \times 10^{6}\right)$ stably overexpressing miR-142$3 p$ or NC were subcutaneously injected into nude mice $(n=5)$, and tumors were harvested after 25 days. Representative tumors were shown in (A). (B) Tumor volume was assessed every 5 days. (C) Tumor weight. (D) Levels of miR-142-3p in xenograft tumors were examined by qRT-PCR. (E) Western blotting analysis of HMGA1 protein in miR-142-3p-overexpressing and control xenograft tumors. ${ }^{*} P<0.05$.

inhibits pancreatic cancer cell proliferation through downregulating HSP70 expression [20]. In osteosarcoma, Namløs et al. showed that miR-142-3p was downregulated in osteosarcoma 
Fig. 7. Downregulation of HMGA1 suppresses tumor growth in vivo. HOS cells $\left(2 \times 10^{6}\right)$ stably overexpressing HMGA1 siRNA or NC were subcutaneously injected into nude mice $(n=5)$, and the tumor growth curve was measured every 5 days for 25 days after inoculation.

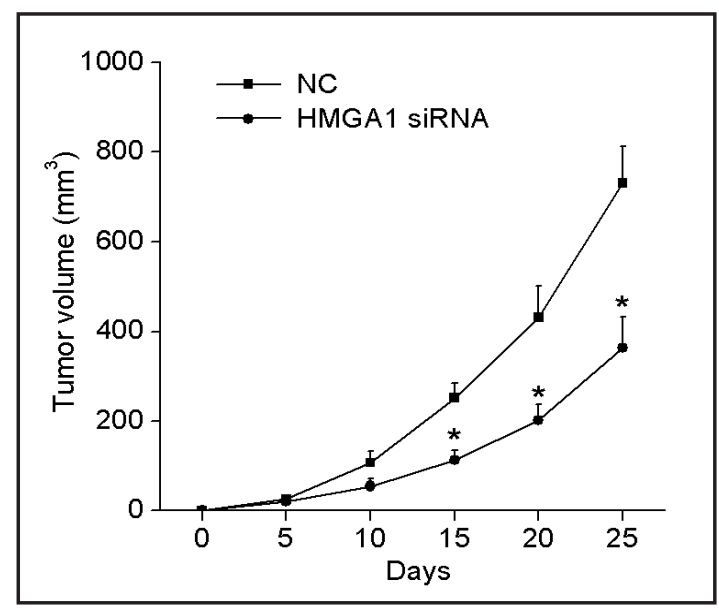

cell lines compared to normal bone tissues using miRNA arrays [21]. However, no further expression or functional confirmation of miR-142-3p in osteosarcoma has been reported.

In this study, we reported that miR-142-3p was significantly downregulated in all five osteosarcoma cell lines compared to normal human osteoblasts, which was consistent with publically data available on the website (www.microRNA.org). Similarly, the overall average expression levels of miR-142-3p were lower in primary samples compared to normal tissues. Overexpression of miR-142-3p in osteosarcoma cells suppressed cell proliferation and colony formation, and inhibited cell migration and invasion. In vivo assays showed that miR142-3p-overexpressing HOS cells were significantly less tumorigenic than the control cells. These findings support the view that miR-142-3p mainly functions as a tumor suppressor in osteosarcoma.

We further investigated the function of miR-142-3p through identifying its target genes. Using bioinformatics analysis, HMGA1 was predicted to be a potential target of miR-142$3 p$ based on identification of conserved binding sites. We performed luciferase reporter assays and observed that luciferase activity was significantly decreased after co-transfection of the miR-142-3p minics and a HMGA1 3'-UTR vector containing the miR-142-3p target sequence. We also found that miR-142-3p overexpression downregulated the expression of HMGA1 mRNA and protein. Furthermore, we analyzed the correlation between miR-142$3 p$ expression and HMGA1 expression in osteosarcoma tissues and identified a significantly reverse correlation. These results proved that HMGA1 was a direct target of miR-142-3p.

HMGA1 encodes a non-histone DNA-binding protein which exists in two isoforms as a result of alternative splicing of RNA. Both bind to AT-rich chromatin regions and modulate gene expression by altering chromatin structure, modulating interactions with promoter and enhancer regions and organizing formation of transcription factor complexes. Expression of HMGA1 is normally low or absent in adult tissues, but HMGA1 is highly expressed in embryonic and adult stem cells and in various cancers [24-26]. HMGA1 is necessary for tumor-promoter-induced transformation and enhances tumor growth and invasion, which is opposite of the role of miR-142-3p [24-28]. Conversely, silencing of HMGA1 has been demonstrated to suppress tumor cell proliferation and invasion [29]. In this study, we identified HMGA1 as a functional target of miR-142-3p. We verified the positive effects of HMGA1 on osteosarcoma cell proliferation, migration and invasion using RNA interference. Our result was similar to Yuan and colleagues' findings, who reported that silencing of HMGA1 was able to suppress osteosarcoma growth [30]. Moreover, the inhibitory effects exerted by miR-142-3p on proliferation, migration and invasion were reversed partially after HMGA1 overexpression.

In summary, our results suggest that miR-142-3p is down-regulated in osteosarcoma, and functions as a tumor suppressor in osteosarcoma cells by targeting HMGA1. Restoration of miR-142-3p might represent a useful therapeutic approach for targeting osteosarcoma. 


\title{
Acknowledgements
}

\author{
This study was supported by National Natural Foundation of China (No. \\ 81371974).
}

\section{References}

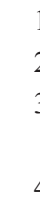

Ottaviani G, Jaffe N: The epidemiology of osteosarcoma. Cancer Treat Res 2009;152:3-13.

Kansara M, Thomas DM: Molecular Pathogenesis of Osteosarcoma. DNA Cell Biol 2007;26:1-18.

Gorlick R: Current concepts on the molecular biology of osteosarcoma. Cancer Treat Res 2009;152:467-

478.

4 Osaki M, Takeshita F, Sugimoto Y, Kosaka N, Yamamoto Y, Yoshioka Y, Kobayashi E, Yamada T, Kawai A, Inoue T, Ito H, Oshimura M, Ochiya T: MicroRNA-143 Regulates Human Osteosarcoma Metastasis by Regulating Matrix Metalloprotease-13 Expression. Mol Ther 2011;19:1123-1130. Bartel DP: MicroRNAs: genomics, biogenesis, mechanism, and function. Cell 2004;116:281-297. Calin GA, Croce CM: MicroRNAs and chromosomal abnormalities in cancer cells. Oncogene 2006;25:62026210.

7 Esquela-Kerscher A, Slack FJ: Oncomirs - microRNAs with a role in cancer. Nat Rev Cancer 2006;6:259269.

8 Ambros V: MicroRNA pathways in flies and worms: growth, death, fat, stress, and timing. Cell 2003;113:673-676.

-9 Lu J, Getz G, Miska EA, Alvarez-Saavedra E, Lamb J, Peck D, Sweet-Cordero A, Ebert BL, Mak RH, Ferrando AA, Downing JR, Jacks T, Horvitz HR, Golub TR: MicroRNA expression profiles classify human cancers. Nature 2005; 435:834-838.

- 10 Song B, Wang Y, Xi Y, Kudo K, Bruheim S, Botchkina GI, Gavin E, Wan Y, Formentini A, Kornmann M, Fodstad O, Ju J: Mechanism of chemoresistance mediated by miR-140 in human osteosarcoma and colon cancer cells. Oncogene 2009;28:4065-4074.

11 Jones KB, Salah Z, Del Mare S, Galasso M, Gaudio E, Nuovo GJ, Lovat F, LeBlanc K, Palatini J, Randall RL, Volinia S, Stein GS, Croce CM, Lian JB, Aqeilan RI: miRNA signatures associate with pathogenesis and progression of osteosarcoma. Cancer Res 2012;72:1865-1877.

12 Gougelet A, Pissaloux D, Besse A, Perez J, Duc A, Dutour A, Blay JY, Alberti L: Micro-RNA profiles in osteosarcoma as a predictive tool for ifosfamide response. Int J Cancer 2010;129:680-690.

13 Duan Z, Choy E, Harmon D, Liu X, Susa M, Mankin H, Hornicek F: MicroRNA-199a-3p is downregulated in human osteosarcoma and regulates cell proliferation and migration. Mol Cancer Ther 2011;10:1337-1345.

14 Zhao G, Cai C, Yang T, Qiu X, Liao B, Li W, Ji Z, Zhao J, Zhao H, Guo M, Ma Q, Xiao C, Fan Q, Ma B: MicroRNA-221 induces cell survival and cisplatin resistance through PI3K/Akt pathway in human osteosarcoma. PLoS One 2013;8:e53906.

-15 Chen L, Wang Q Wang GD, Wang HS, Huang Y, Liu XM, Cai XH: miR-16 inhibits cell proliferation by targeting IGF1R and the Raf1-MEK1/2-ERK1/2 pathway in osteosarcoma. FEBS Lett 2013;587:13661372.

-16 van der Deen M, Taipaleenmäki H, Zhang Y, Teplyuk NM, Gupta A, Cinghu S, Shogren K, Maran A, Yaszemski MJ, Ling L, Cool SM, Leong DT, Dierkes C, Zustin J, Salto-Tellez M, Ito Y, Bae SC, Zielenska M, Squire JA, Lian JB, Stein JL, Zambetti GP, Jones SN, Galindo M, Hesse E, Stein GS, van Wijnen AJ: MicroRNA-34c inversely couples the biological functions of the runt-related transcription factor RUNX2 and the tumor suppressor p53 in osteosarcoma. J Biol Chem 2013;288:21307-21319.

17 Wu L, Cai C, Wang X, Liu M, Li X, Tang H: MicroRNA-142-3p, a new regulator of RAC1, suppresses the migration and invasion of hepatocellular carcinoma cells. FEBS Lett 2011;585:1322-1330.

18 Wang F, Wang XS, Yang GH, Zhai PF, Xiao Z, Xia LY, Chen LR, Wang Y, Wang XZ, Bi LX, Liu N, Yu Y, Gao D, Huang BT, Wang J, Zhou DB, Gong JN, Zhao HL, Bi XH, Yu J, Zhang JW: miR-29a and miR-142$3 p$ downregulation and diagnostic implication in human acute myeloid leukemia. Mol Biol Rep 2012;39:2713-2722.

19 Shen WW, Zeng Z, Zhu WX, Fu GH: MiR-142-3p functions as a tumor suppressor by targeting CD133, ABCG2, and Lgr5 in colon cancer cells. J Mol Med (Berl) 2013;91:989-1000. 


\begin{tabular}{|c|c|c|}
\hline Cellular Physiology & Cell Physiol Biochem 2014;33:1329-1339 & \\
\hline and Biochemistry & $\begin{array}{l}\text { DOI: 10.1159/000358700 } \\
\text { Published onine: AprI Z8, } 2014\end{array}$ & $\begin{array}{l}\text { O } 2014 \text { S. Karger AG, Basel } \\
\text { www.karger.com/cpb }\end{array}$ \\
\hline
\end{tabular}

20 MacKenzie TN, Mujumdar N, Banerjee S, Sangwan V, Sarver A, Vickers S, Subramanian S, Saluja AK: Triptolide induces the expression of miR-142-3p: a negative regulator of heat shock protein 70 and pancreatic cancer cell proliferation. Mol Cancer Ther 2013;12:1266-1275.

-21 Namløs HM, Meza-Zepeda LA, Barøy T, Østensen IH, Kresse SH, Kuijjer ML, Serra M, Bürger H, CletonJansen AM, Myklebost O: Modulation of the osteosarcoma expression phenotype by microRNAs. PLoS One 2012;7:e48086.

22 Shen K, Liang Q, Xu K, Cui D, Jiang L, Yin P, Lu Y, Li Q, Liu J: MiR-139 inhibits invasion and metastasis of colorectal cancer by targeting the type I insulin-like growth factor receptor. Biochem Pharmacol 2012;84:320-330.

-23 Fedele M, Fusco A: HMGA and cancer. Biochim Biophys Acta 2010;1799:48-54.

-24 Wood LJ, Mukherjee M, Dolde CE, Xu Y, Maher JF, Bunton TE, Williams JB, Resar LM: HMG-I/Y: A new c-Myc target gene and potential human oncogene. Mol Cell Biol 2000;20:5490-5502.

25 Reeves R, Edberg DD, Li Y: Architectural transcription factor HMGI(Y) promotes tumor progression and mesenchymal transition of human epithelial cells. Mol Cell Biol 2001;21:575-594.

26 Xu Y, Sumter TF, Bhattacharya R, Tesfaye A, Fuchs EJ, Wood LJ, Huso DL, Resar LM: The HMG-I oncogene causes highly penetrant, aggressive lymphoid malignancy in transgenic mice and is overexpressed in human leukemia. Cancer Res 2004;64:3371-3375.

27 Wood LJ, Maher JF, Bunton TE, Resar LM: The oncogenic properties of the HMG-I gene family. Cancer Res 2000;60:4256-4261.

-28 Fedele M, Pentimalli F, Baldassarre G, Battista S, Klein-Szanto AJ, Kenyon L, Visone R, De Martino I, Ciarmiello A, Arra C, Viglietto G, Croce CM, Fusco A: Transgenic mice overexpressing the wild-type form of the HMGA1 gene develop mixed growth hormone/prolactin cell pituitary adenomas and natural killer cell lymphomas. Oncogene 2005;24:3427-3435.

-29 Shah SN, Cope L, Poh W, Belton A, Roy S, Talbot CC Jr, Sukumar S, Huso DL, Resar LM: HMGA1: A Master Regulator of Tumor Progression in Triple-Negative Breast Cancer Cells. PLoS One 2013;8:e63419.

30 Yuan S, Pan Q Fu C, Bi Z: Silencing of HMGA1 expression by RNA interference suppresses growth of osteogenic sarcoma. Mol Cell Biochem 2011;355:281-287. 